\title{
Post-weaning migration of northern fur seal Callorhinus ursinus pups from the Pribilof Islands, Alaska
}

\author{
Jason D. Baker* \\ Pacific Islands Fisheries Science Center, National Marine Fisheries Service, NOAA, 2570 Dole Street, Honolulu, \\ Hawaii 96822-2326, USA
}

\begin{abstract}
The post-weaning migration of northern fur seal Callorhinus ursinus pups from the Pribilof Islands in the eastern Bering Sea was investigated using satellite-linked dive recorders deployed in November 1996 and 1997, with tracking duration ranging up to more than 6 mo. Prior to abruptly departing on the migration by early December, pups did not stray far from their natal islands. After a median travel time of $17 \mathrm{~d}$, most pups transited various Aleutian Island passes, though 3 animals remained in the Bering Sea until at least late January. Pups that left the Bering Sea subsequently dispersed into a vast area of the North Pacific some $2500 \mathrm{~km}$ wide from the central Aleutians to the Gulf of Alaska and $1000 \mathrm{~km}$ from 60 to $45^{\circ} \mathrm{N}$. Most pups remained in offshore pelagic areas; however, 3 individuals also spent time over continental shelf waters. While the spatial dispersion and habitats used by migrating pups varied considerably, their diving behavior was remarkably consistent. All migrating pups dove largely during the night, and during evening and morning hours, but practically ceased diving during the day, suggesting they foraged on vertically migrating prey that is unattainable or too costly to reach during daytime. Dives were typically shallow and brief; $77 \%$ reached depths less than $10 \mathrm{~m}$, and $81 \%$ lasted less than $1 \mathrm{~min}$. Wide dispersal presents a potential selective mechanism for differential survival, in that benefits (food availability) and risks (storms, predation, and, potentially, fishery interactions) likely vary considerably across the oceanic habitats occupied by these naive foragers on their first migration.
\end{abstract}

KEY WORDS: Callorhinus ursinus $\cdot$ Northern fur seal $\cdot$ Migration $\cdot$ Diving behavior

\section{INTRODUCTION}

Advances in telemetry have revealed striking insights into the individual movements and ecology of highly migratory species (e.g. Weimerskirch \& Wilson 2000, McGrady et al. 2002, Block et al. 2005, Weng et al. 2005, Polovina et al. 2006, Shaffer et al. 2006). These methods are being increasingly applied to investigate juvenile dispersal, a critical, but poorly understood, life stage in long-distance migratory species (e.g. Kooyman et al. 1996, McConnell et al. 2002, Barbraud et al. 2003, Clarke et al. 2003, Hake et al. 2003, Weimerskirch et al. 2006).

A highly migratory otariid, the northern fur seal Callorhinus ursinus congregates on several islands in the
North Pacific to breed and rear its young from roughly July through November (Bartholomew \& Hoel 1953, Peterson 1968, Gentry \& Holt 1986). Approximately $70 \%$ of the world's population of northern fur seals breeds on the Pribilof Islands, Alaska, in the eastern Bering Sea (Loughlin et al. 1994). From December to April, northern fur seals are virtually absent from the breeding islands and range throughout the North Pacific from the Bering Sea southward to southern California and Japan and perhaps all points between (Kenyon \& Wilke 1953, Ream et al. 2005).

Until recently, northern fur seal migration patterns were inferred primarily from 19th-century pelagic sealing records and at-sea research collections conducted from the 1950s to the 1970s (Kenyon \& Wilke 
1953, Bigg 1990). These data sources, however, were highly biased toward nearshore areas and regions where both sealers and researchers knew they would encounter seals of preferred size and age. While they were by no means representative of the northern fur seal's entire range, age and sex-specific migratory patterns have nevertheless been inferred from these pelagic collections. Most of the Pribilof Islands population was thought to leave the islands by November-December and proceed more or less directly to the south, exiting the Bering Sea primarily through Unimak Pass (Kenyon \& Wilke 1953). Subsequently, most seals appeared to make their way eastward toward the Gulf of Alaska, then southward along the continental shelf of western North America. Adult males tended to remain in more northerly areas (Bering Sea and Gulf of Alaska), whereas adult females and juveniles of both sexes proceeded further south (Kenyon \& Wilke 1953, Bigg 1990). Tag recoveries indicated that some seals from the Pribilofs migrate to the western North Pacific off Japan. Pups born the previous summer were conspicuously under-represented in pelagic research collections, leading Kenyon \& Wilke (1953) and Bigg (1990) to conclude that pups and yearlings likely tend to remain farther offshore.

More recently, satellite telemetry studies have documented the migratory paths of adult fur seals. Loughlin et al. (1999) tracked 8 adult male seals from the Pribilofs, confirming that they remained in North Pacific waters in the Bering Sea, Gulf of Alaska, and near the Kuril Islands, Russia. Baba et al. (2000) tracked 1 subadult and 2 adult females for approximately 2 mo from the Commander Islands, Russia, into a broad area of the western and central North Pacific. Ream et al. (2005) tracked 13 adult female fur seals from the Pribilof Islands for up to $8 \mathrm{mo}$, encompassing the entire return migration for 2 animals. They found that all of the females departed the Bering Sea via Unimak Pass by 1 January, and most made their way to winter foraging areas off the west coast of North America between Vancouver Island, Canada, and southern California. Three females remained far out to sea in the North Pacific Transition Zone.

In contrast, the migratory behavior of northern fur seal pups remains largely unstudied. Pups wean at approximately 4 mo of age (Peterson 1968, Gentry \& Holt 1986) and then depart from their natal islands and embark on their first migration. Unlike older animals, however, fur seal pups are faced with immense challenges. They are newly independent foragers and naive migrators, having never been away from their natal islands. Moreover, these small marine mammals, weighing less than $20 \mathrm{~kg}$ on average (Goebel 2002), take to the Bering Sea in late autumn when water and air temperatures are low and dropping and powerful storms are common. Pups maintain a pelagic existence and do not return to their natal islands until they are 14 mo to a few years old (Kenyon \& Wilke 1953, Bigg 1990), by which time their numbers have been greatly reduced. More than half the pups that wean perish in the first 20 mo after migration, and most of the mortality is believed to occur during the first winter at sea (Lander 1979).

Ragen et al. (1995) first documented the initial migration route and timing of individual northern fur seal pups. In November 1989 and 1990, they attached VHF radio transmitters to 184 pups on St. Paul Island and subsequently attempted to locate them in several Aleutian passes using automated receiving stations and aerial overflights. They located 70 pups near the Aleutians and estimated that the mean travel time from the Pribilofs to the Aleutians was $11 \mathrm{~d}$. They determined that pups traveled through several Aleutian passes and that Unimak Pass was not the primary route.

The Pribilof Islands fur seal population was greatly reduced from its historic, known maximum in the late 1950s as a result of directed killing of females between 1956 and 1964 (York \& Hartley 1981). The population began to increase after this practice was terminated, but then inexplicably declined from the mid-1970s into the early 1980s. Following a period of relative stability, recent surveys indicate a renewed unexplained decline of $6 \% \mathrm{yr}^{-1}$ in pups born on the Pribilof Islands between 1998 and 2004 (Towell et al. 2006). While the reasons for the declines are unknown, low juvenile survival is a potential proximate cause.

Given the downward trend in this already depleted population, conservation of northern fur seals requires diagnosis and potentially mitigation of the current decline. An important step in that process is to characterize the least known and perhaps most critical segment of the species' life history-the post-weaning migration.

This study presents the first information on movements and diving behavior of migrating northern fur seal pups using satellite-linked time depth recorders (SLTDRs). The study was conducted to investigate several aspects of the early migration period. First, premigration behavior was described with respect to the distance pups traveled away from their natal islands and their diving behavior prior to embarking on their first migration. Second, the route and timing of the migration was determined as the pups made their way from the natal islands. Subsequently, the winterspring distribution and habitats used by these young animals were identified and their diving behavior was characterized. Migratory patterns of pups were assessed relative to the information documented for older animals to potentially aid in determining where 
distinctions in distribution and habitat use may occur. Because of the limited sample size, the analyses presented here are largely descriptive.

\section{MATERIALS AND METHODS}

The Pribilof Islands are located in the eastern Bering Sea approximately $400 \mathrm{~km}$ north of the Aleutian Island Chain and $500 \mathrm{~km}$ west of mainland Alaska. Approximately 180000 and 25000 northern fur seal pups were born on St. Paul and St. George Islands, respectively, in 1996, the first year of this study.

SLTDRs were attached to 20 northern fur seal pups. Recognizing that the total sample size for the study would likely prove too small to make statistical comparisons of migratory behavior from distinct breeding areas (there are 14 and 6 recognized rookeries on St. Paul and St. George Islands, respectively) study animals were selected from a variety of locations to represent the overall Pribilof Island population. During 10-12 November 1996, 8 pups were tagged (4 males, 4 females) on St. Paul Island. During 8-13 November 1997, 8 additional SLTDRs were attached to St. Paul Island pups ( 5 males, 3 females) and 4 were attached to St. George Island pups (2 males, 2 females). Fewer pups were tracked from St. George Island, reflecting the relatively small proportion of the population born there. Pups were selected from a sampling of the breeding areas on each island. Both sets of tagged pups were followed for periods spanning parts of 2 calendar years. For brevity, in this paper 1996 refers to instruments deployed in November 1996 and transmitting into 1997; 1997 refers to deployments in November 1997 transmitting into 1998.

Given that few SLTDRs were available and that pups have high mortality rates during the first winter at sea (Lander 1979), study subjects were not chosen randomly. Rather, pups were chosen from the high end of the available size range (minimum acceptable mass was $18 \mathrm{~kg}$ ) to maximize the chances of having survivors in the sample and to minimize the relative effect of increased hydrodynamic drag from the SLTDR. Only pups that appeared robust, healthy, and free of wounds were considered for this study.

Pups were captured by hand, weighed, measured (standard length and axillary girth), and placed in a restraining device. SLTDRs were glued to the pup's mid-back with 5-minute epoxy. The leading edge of the instrument was positioned just posterior to the midpoint of an imaginary line connecting the positions where the posterior edges of the fore flippers meet the torso. This area of the back tends to remain relatively straight when pups walked or swam, which likely reduces stress between the flexible seal's body and the rigid instrument and perhaps resulting in a longer duration of attachment and less discomfort for the animals. This area of the back also stays frequently above water when pups are at the surface, which is advantageous for data transmission.

We used 0.25 W SLTDRs (Wildlife Computers) ${ }^{\underline{1}}$. The instruments weighed approximately $165 \mathrm{~g}$ and were $10.7 \mathrm{~cm}$ long, $4.5 \mathrm{~cm}$ wide, and $2.3 \mathrm{~cm}$ high, with a $19.5 \mathrm{~cm}$ antenna. The units were programmed to provide location and dive behavior data via the Argos satellite data collection system (Service Argos 1996). The SLTDRs were programmed to transmit every other day to extend battery life. Dive data were stored during the off day and transmitted the following day. All dates reported reference GMT. Locations processed by Service Argos are assigned a quality code, based on the precision of the geographic fix (Service Argos 1996). To minimize error from poor quality locations, we used only class 0 to class 3 locations, which on average are likely to be precise to $<5 \mathrm{~km}$ (Robson et al. 2004).

The SLTDRs summarized and transmitted dive data in histograms of three types: Dive duration, maximum dive depth, and proportion of time spent within various depth ranges (time-at-depth histograms). Dive histograms were coded to represent four $6 \mathrm{~h}$ periods, roughly corresponding to night (21:00-03:00 h), morning (03:00-09:00 h), day (09:00-15:00 h), and evening (15:00-21:00 h). These time periods were referenced to GMT minus $11 \mathrm{~h}$, which is appropriate for $165-170^{\circ} \mathrm{W}$, where the Pribilof Islands are located. Other transmissions contained information on the functional status of the instrument and reported on the maximum depth reached during the preceding $24 \mathrm{~h}$.

The SLTDRs measured depth to the nearest $1 \mathrm{~m}$ and dives were defined as submersion to depths of at least $2 \mathrm{~m}$. Dive durations were summarized in the following histogram bins: $<1,1-2,2-3,3-4,4-5$, and $>5$ min. Maximum dive depths were summarized in the following bins: $2-5,6-10,11-25,26-50,51-100$, and $>100 \mathrm{~m}$. The maximum possible value in a dive duration or maximum depth bin was 255, so that if more than 255 dives to a given depth or duration range were completed in a $6 \mathrm{~h}$ period, the corresponding histogram bin would still record 255. Time-at-depth histograms summarized the proportion of each $6 \mathrm{~h}$ period spent at the following depths: Surface-1, 2-5, 6-10, $11-25,26-50,51-100,>100 \mathrm{~m}$. Because the time-atdepth histograms reported proportions, maximum bin value was not an issue.

The onset of migration (time of departure from the natal island) was estimated as the mid-point between

1Reference to trade names does not constitute endorsement by the National Marine Fisheries Service, NOAA 
the last time a location was received from an individual at the island and the first at-sea location after which the pup did not return. The first time a pup was located south of the Aleutian Islands was considered the time of departure from the Bering Sea.

\section{RESULTS}

\section{Pre-migration period}

Of the 20 pups captured for this study, 11 were male and 9 were female. The males weighed $22 \mathrm{~kg}$ and measured $93 \mathrm{~cm}$ long and $76 \mathrm{~cm}$ in girth on average, while the comparable statistics for females were $20 \mathrm{~kg}$, $89 \mathrm{~cm}$, and $73 \mathrm{~cm}$, respectively. Two SLTDRs failed prior to departure, so the onset of migration was estimated from the remaining 18 pups. Dates of departure ranged from 9 November to 3 December (median was 17 November). The average time from instrumentation until departure was $7 \mathrm{~d}(\mathrm{SD}=6 \mathrm{~d}$, range $14 \mathrm{~h}$ to $23 \mathrm{~d}$ ).

During the period prior to migration, pups went to sea regularly, as indicated by location fixes, but usually stayed quite near their capture site and close to shore. Perhaps because high cliffs around the island blocked signal reception, only one pup captured at St. George Island had location fixes prior to migration. This apparent blocking of signals did not occur on the lower profile St. Paul Island. Of 15 pups with atsea location fixes prior to migration, the average maximum distance pups traveled from their respective capture sites was $10.3 \mathrm{~km}$ (maximum $22.0 \mathrm{~km}$ ), and the average maximum distance observed from nearest shore was $4.5 \mathrm{~km}$ (maximum $17.6 \mathrm{~km}$ ). In most cases, the locations furthest from shore were of the lowest quality code (0), suggesting that error in the Argos locations may have inflated even these modest characterizations of pre-migration ranging.

\section{Migration routes and timing}

To determine whether pup movements had a random or a significantly directional pattern at the start of migration, the directional vector representing each seal's displacement $4 \mathrm{~d}$ after departure from the natal rookery was calculated. The mean initial bearing for pups in 1996 was approximately southwest $\left(220^{\circ}, \mathrm{N}=\right.$ 6 , angular deviation $55^{\circ}$ ). In 1997 , the mean direction was southeast $\left(137^{\circ}, \mathrm{N}=\right.$
11, angular deviation $50^{\circ}$ ). Using Rayleigh's Z-test (Zar 1984), the early migration direction of pups in 1996 was not statistically different from random $(0.10<p<0.20)$, while significant directionality was detected in the larger 1997 sample $(0.01<\mathrm{p}<0.02)$. The mean direction of early travel by pups differed significantly between the 2 years (Watson and Williams test, Zar 1984, $0.025<\mathrm{p}<$ 0.05). Pups moved an average of $46 \mathrm{~km} \mathrm{~d}^{-1}$ during the first 4 days of migration.

Eleven seals were tracked as they passed through the Aleutian Islands and into the North Pacific Ocean (Fig. 1). Their median time from onset of migration until leaving the Bering Sea was $17 \mathrm{~d}$; however, 4 remained in the Bering Sea for extended periods from 46 to $69 \mathrm{~d}$ or more until at least late January (2 were still in the Bering Sea when their instruments stopped transmitting). All three 1996 pups tracked out of the Bering Sea transited 3 adjacent central Aleutian passes (Seguam Pass, Amukta Pass, and an unnamed passage between Yunaska Island and the Islands of the Four Mountains) to the southwest of the Pribilof Islands. In contrast, all eight 1997 pups exited the Bering Sea through 3 other adjacent passes in the eastern Aleutians to the southeast of the Pribilofs (six through Unimak Pass, 1 through Akutan Pass, and 1 animal navigated a $3 \mathrm{~km}$ channel between Akutan and Akun Islands). The 2 groups of passes used exclusively in the 2 years were separated by a minimum of $304 \mathrm{~km}$.

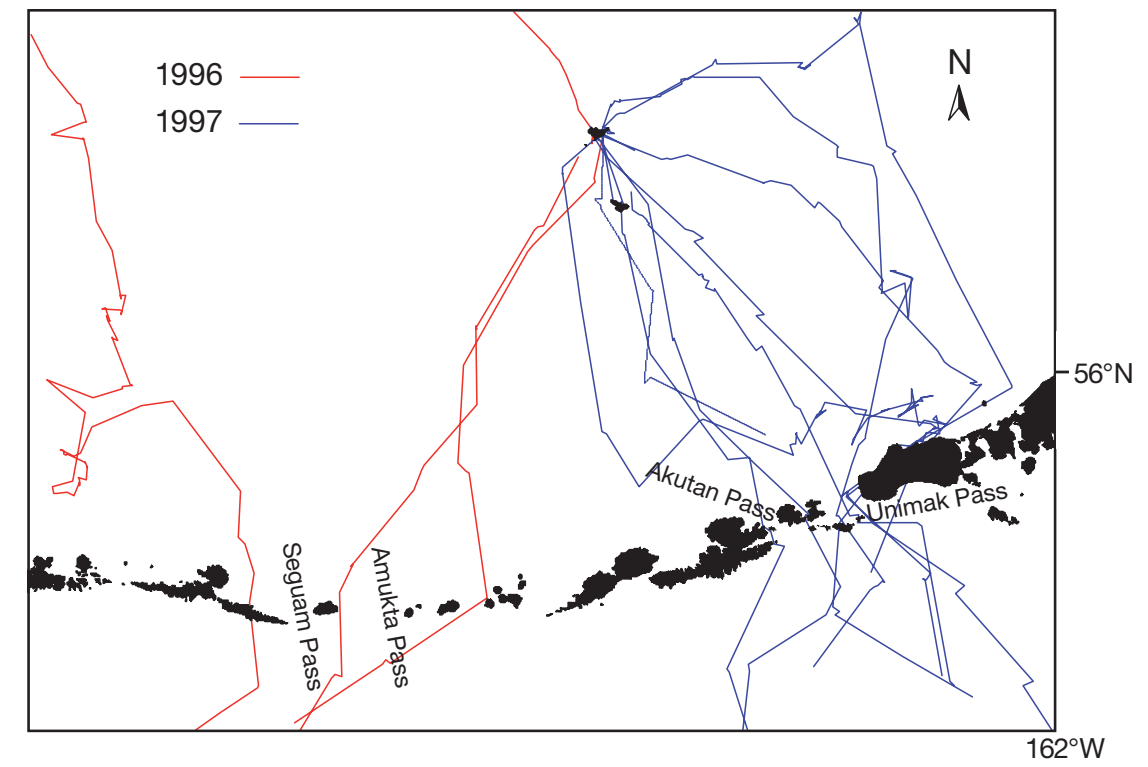

Fig. 1. Callorhinus ursinus. Migration tracks of northern fur seal pups passing between the Aleutian Islands $(1996 \mathrm{~N}=3$ shown in red, $1997 \mathrm{~N}=8$ shown in blue). Tracks begin from the pups' natal sites in the Pribilof Islands, Alaska (St. Paul Island to the north and St. George Island to the south). Because location data were received every other day, interpolated tracks sometimes appear to cross land. One animal's path from St. Paul Island to the northwest (in red) extended beyond the range of this figure and subsequently reappeared (westernmost track on the figure, see also Fig. 2B, purple track) 
Although the sample size in 1996 was very small, the dichotomy in routes used in 1996 and 1997 was a significant departure from what one would expect if pups had randomly used the 2 groups of passes in both years (Fisher's exact test, $\mathrm{p}=0.006$ ). Notably, while the routes followed from the natal islands to the Aleutians were sometimes meandering and indirect, the passes used in the 2 years (to the southwest in 1996 and to the southeast in 1997) ultimately reflected the difference in mean initial bearing $4 \mathrm{~d}$ after the onset of migration.

The 11 pups that left the Bering Sea were subsequently tracked for varying lengths of time with final transmissions ranging from 23 January to 13 May. Individual tracks were highly variable, but a few generalizations emerged regarding movement patterns. The pups occupied a vast area spanning approximately $1000 \mathrm{~km}$ north to south (from almost $60^{\circ} \mathrm{N}$ down to just south of $45^{\circ} \mathrm{N}$ ) and $2500 \mathrm{~km}$ wide from the central Aleutians to the eastern Gulf of Alaska, and encompassing several habitats (Fig. 2A). Of the 11 animals leaving the Bering Sea, 9 subsequently made a turn to the east or southeast, none turned to the west. However, in general, the routes taken by pups did not exhibit sustained directionality; rather, they meandered and seemed to alternate periods of transit with more sedentary spells (Fig. 3). Typically, pups remained in pelagic waters far from shore, but several used both pelagic areas and coastal Alaska waters in the winter and spring.

The tracks for all seals are depicted in Fig. 2A. Some relatively distinct patterns are shown for the 11 pups that exited the Bering Sea (Fig. 2B-D). Five pups moved into exclusively pelagic waters in a broad area centered roughly on $50^{\circ} \mathrm{N}$ (Fig. 2B). Three other animals traveled in a counter-clockwise direction along large, somewhat circular, routes south of the eastern Aleutian Islands to the Gulf of Alaska (Fig. 2C). These 3 animals spent $1.5-5$ mo in their respective circuits from December to May, a period which included prolonged relatively stationary intervals. The remaining

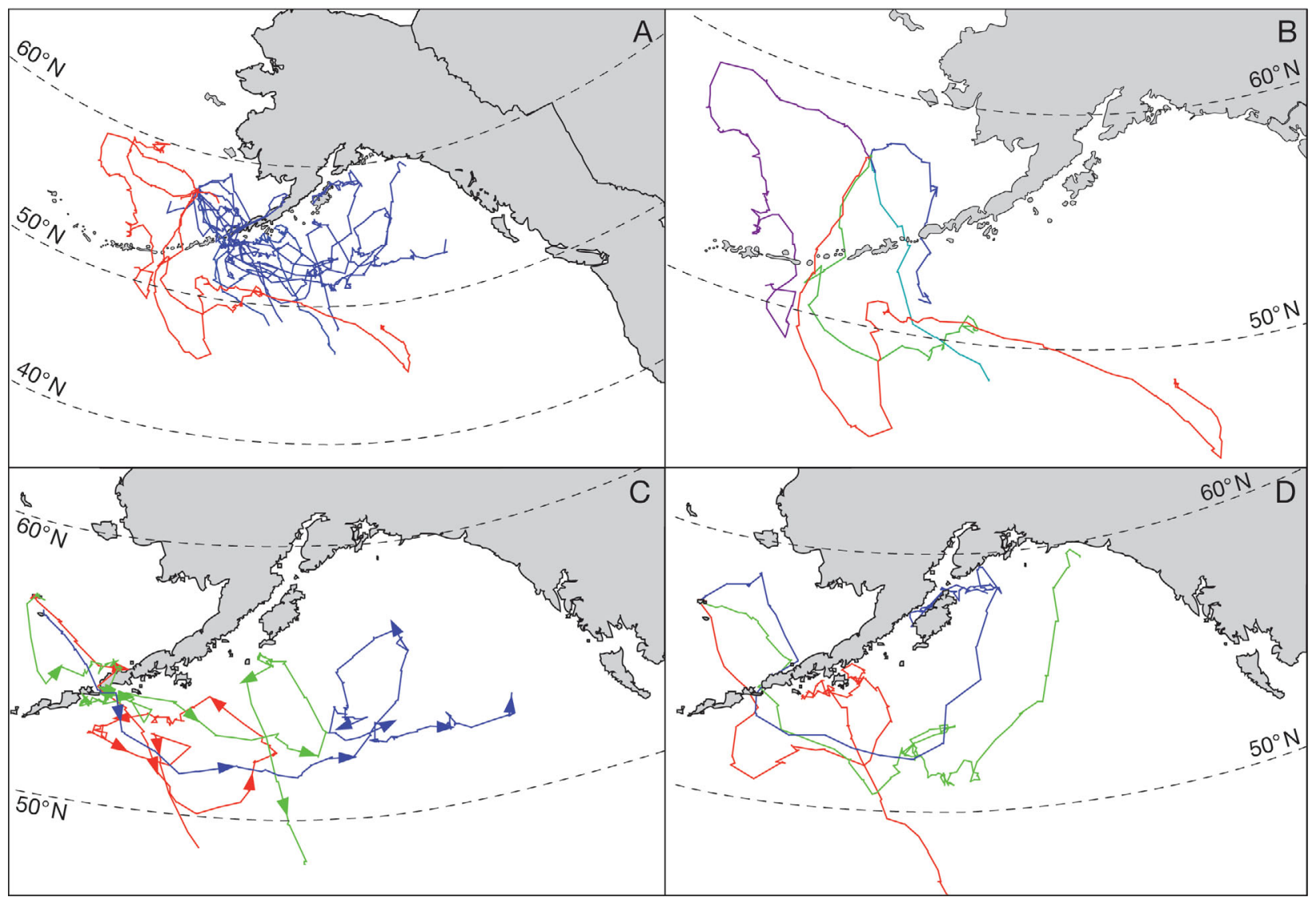

Fig. 2. Callorhinus ursinus. (A) Migration routes of northern fur seal pups from 1996-7 in red and pups from 1997-8 in blue. Subset of (B) 5 (of 11) pups that migrated out of the Bering Sea (96_51,96_52,96_56,97_50,97_56) whose migration routes led to a broad pelagic area roughly centered on $50^{\circ} \mathrm{N}_{i}$ (C) 3 pups $\left(97 \_51,97 \_54,97 \_60\right)$ that stayed in pelagic waters and followed counter-clockwise routes to cover large areas from the Gulf of Alaska to south of the eastern Aleutian Islands; (D) 3 pups (96_55, 97_57,97_58) that used far offshore pelagic areas and coastal waters in the Gulf of Alaska. Line colors (B-D) distinguish individual animals 


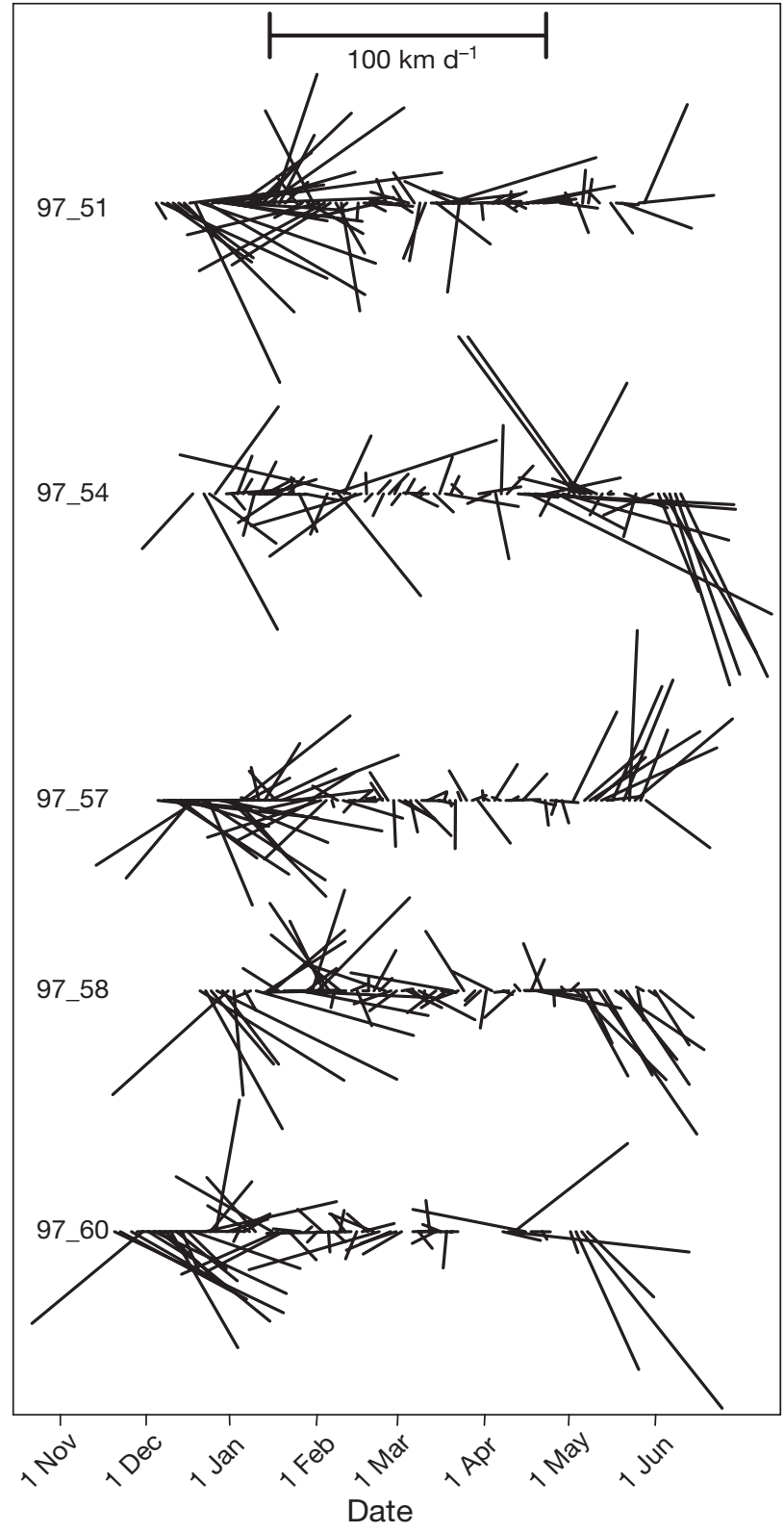

Fig. 3. Callorhinus ursinus. Typical velocity vectors of migrating northern fur seal pups. Vector lengths indicate speed and compass direction is indicated (north is up). Note lack of sustained directionality and periods of movement interspersed with sedentary periods

3 seals traveled well offshore and stayed in pelagic waters for varying lengths of time before moving northward and returning to coastal areas of Alaska (Fig. 2D). One pup spent almost 3 mo (19 January to 13 April) in continental shelf waters near the Shumagin and Sanak Islands. The second animal spent 2.5 mo in shelf waters south of the Kenai Peninsula and in Shelikoff Strait from the end of December until midMarch, when transmissions ceased. The final pup spent 4 mo in a relatively localized pelagic region before rather abruptly turning north, reaching nearly $60^{\circ} \mathrm{N}$ in nearshore waters of the central Gulf of Alaska. The latter 2 animals ended up in latitudes north of the Pribilof Islands many months after having begun their migration.

\section{Diving behavior}

To characterize pre-migration diving behavior, average dive histograms were calculated for each $6 \mathrm{~h}$ period of the day for nine pups. For these pups, histogram data were received on at least $2 \mathrm{~d}$ for each $6 \mathrm{~h}$ time period. Pre-migration diving behavior was consistent among pups. The pups conducted an average of $216(\mathrm{SD}=93)$ dives per day. Most of the dives occurred during the day (09:00-15:00 h, 35\%), somewhat less during morning (03:00-09:00 h, 32\%) and evening
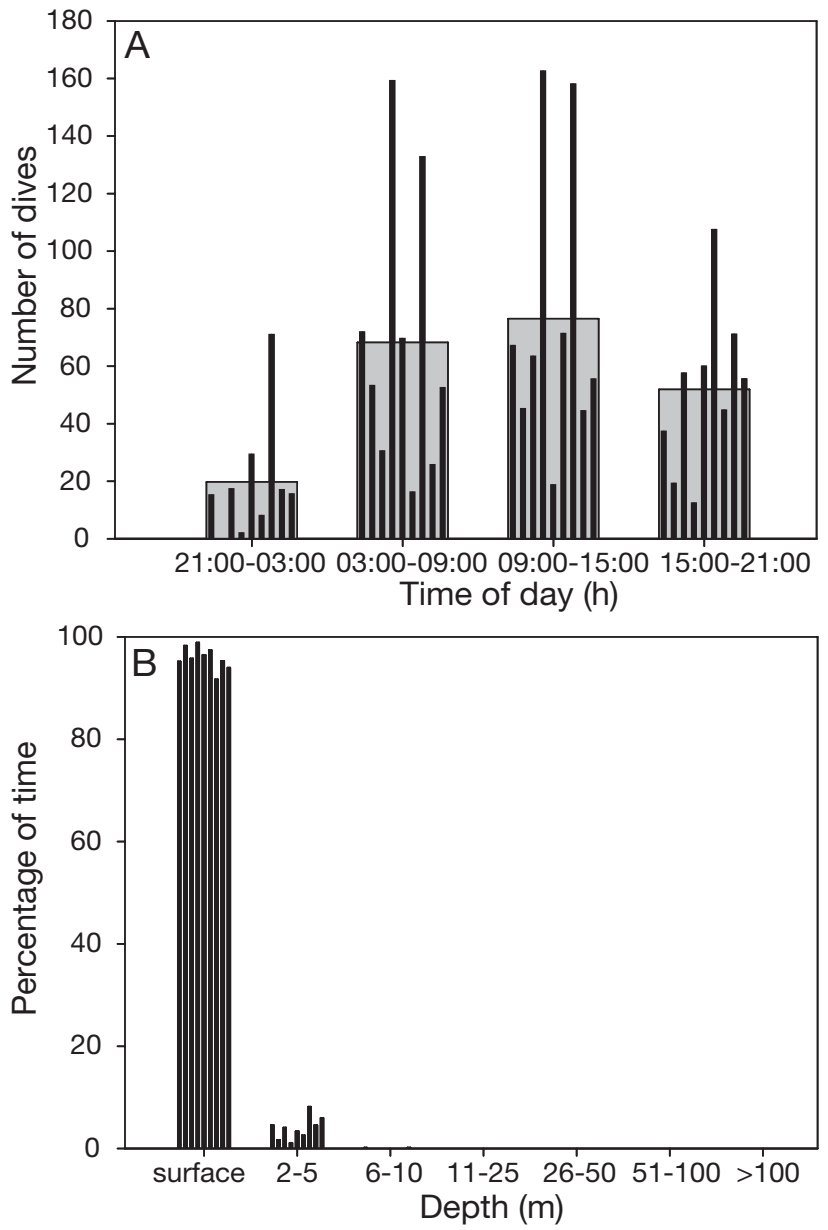

Fig. 4. Callorhinus ursinus. Diving behavior of 9 northern fur seal pups prior to migration. (A) Average number of dives completed per $6 \mathrm{~h}$ period. Each pup's average value shown as thin black bars; large grey bar indicates average of 9 pups. (B) Average percent of each pup's time at depth 
(15:00-21:00 h, 24\%) h, with very few dives during the night (21:00-03:00 h, 9\%, Fig. 4). During the premigration period, sunrise occurred at approximately 07:00 $\mathrm{h}$ and sunset at 15:00 h. Pre-migration dives were extremely shallow (92\% were $2-5 \mathrm{~m}$ in depth) and short in duration (89\% lasted less than 1 min). Prior to migration, pups almost never dived below $10 \mathrm{~m}$ or longer than 2 min and spent an average $96 \%$ of their time on land or at the sea surface (range 92-99\%). The diving records did not indicate change in diving frequency, depth, or duration as the onset of migration approached.
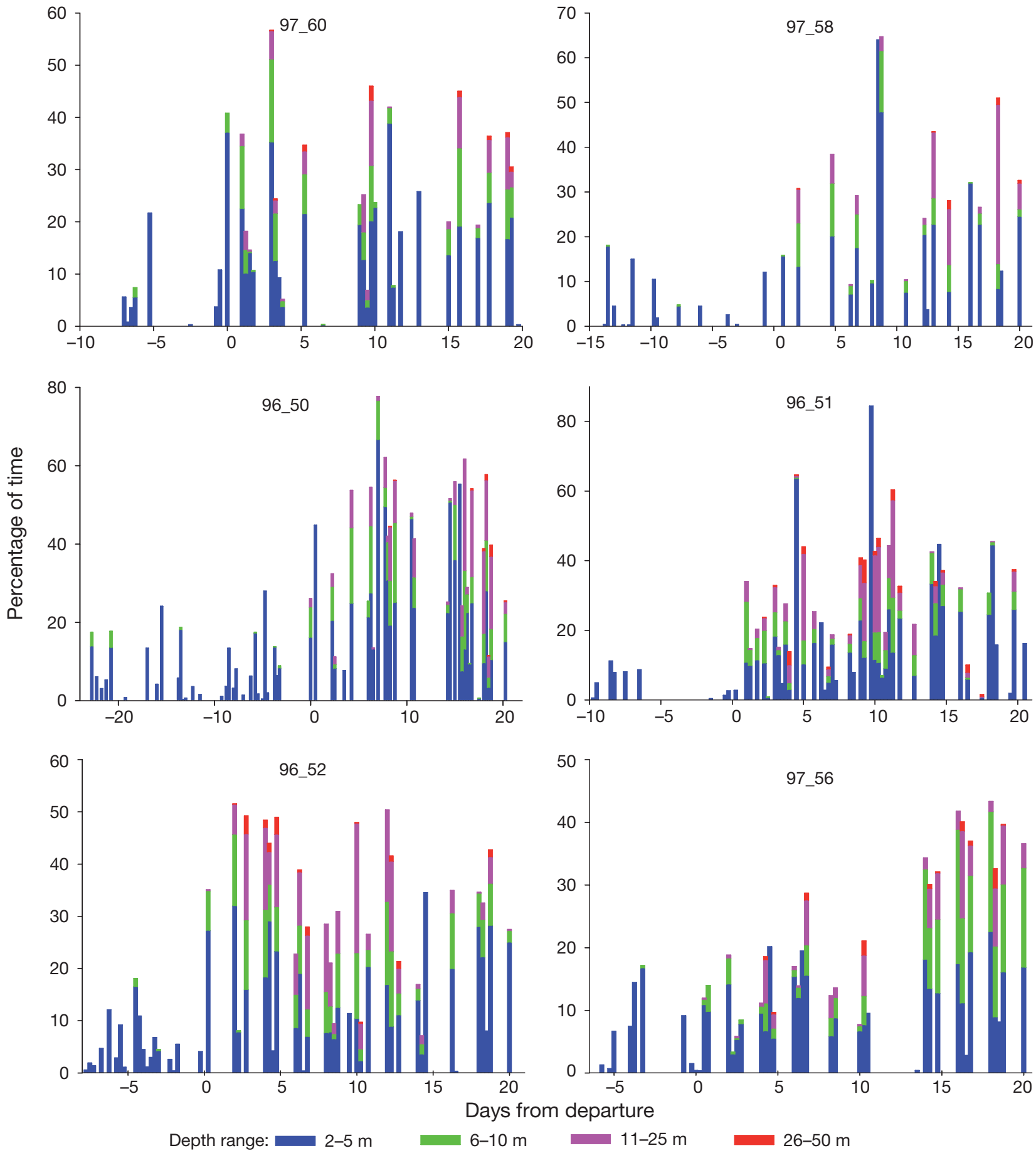

Fig. 5. Callorhinus ursinus. Proportion of time spent at depth by 6 northern fur seal pups prior to and for $20 \mathrm{~d}$ after departure from their natal island. Proportions are shown for each $6 \mathrm{~h}$ period for which data were received. Colored bars distinguish depth ranges. All pups exhibit an abrupt shift in diving behavior after departure 
The onset of migration was associated with an abrupt and marked change in diving behavior. Pups began to spend more time submerged and dived to greater depths immediately after leaving their natal islands (Fig. 5). General characterization of diving behavior during the migration was based on the records of 13 animals tracked for a minimum of $22 \mathrm{~d}$ at sea (Table 1). These animals averaged $536(\mathrm{SD}=90)$ dives $\mathrm{d}^{-1}$, mostly during the night, morning, and evening hours. Migrating pups averaged only 26 (SD = 9) dives during the day $(09: 00-15: 00 \mathrm{~h})$, representing just $5 \%$ of all dives. In contrast, $35 \%$ of all pre-migration dives had occurred during the day. Histograms of maximum dive depth, dive duration, and proportional time at depth are presented in Fig. 6. While there was some variability among individuals, the general patterns were quite similar among the 13 pups. All exhibited a strong daily cycle where diving largely occurred during the night, evening, and morning hours and all but ceased during the day. The dives were typically shallow, with $77 \%$ less than $10 \mathrm{~m}$ and only $1 \%$ exceeding $50 \mathrm{~m}$. Most dives (81\%) lasted less than $1 \mathrm{~min}$ and only $1 \%$ exceeded $3 \mathrm{~min}$. Overall, migrating pups spent $71 \%$ of their time at the surface, $14 \%$ at $2-5 \mathrm{~m}$, $5 \%$ at $6-10 \mathrm{~m}, 6 \%$ at $11-25 \mathrm{~m}$, and $3 \%$ at $26-50 \mathrm{~m}$.

Maximum depth reached during $24 \mathrm{~h}$ periods were drawn from status messages from all migrating pups and plotted against the number of days after onset of migration (Fig. 7). As noted earlier, an abrupt increase in dive depth occurred immediately after onset of migration. A second order polynomial smooth, fitted through the post-migration points for all seals, indicates that maximum dive depth tended to increase during approximately the first $90 \mathrm{~d}$.

\section{DISCUSSION}

This study provides new insights into northern fur seal pup migration, yet a number of caveats should be recognized when interpreting the findings. The sample size was quite small and likely did not capture the range of migratory behavior in the population. Additionally, the robust study subjects selected for their presumed greater chances of survival may have exhibited behavior that differed from smaller animals and those in poor condition (cf. Hindell et al. 1999, Barbroud et al. 2003). The manner in which dive data were collected also involved some shortcomings. The four $6 \mathrm{~h}$ periods were chosen to represent night, morning, day, and evening. However, as the individuals dispersed over large areas and the tracking period spanned autumn to spring, these $6 \mathrm{~h}$ periods covered varying portions of the local photoperiod, depending on geographic position and date. This likely blurred the distinction of diving behavior by time of day. Nevertheless, very low diving efforts during daytime were still apparent. Another issue with maximum depth and duration histogram data was that each bin could only count up to 255 dives. Every pup had at least some histograms in which the lowest order bins (i.e. 2-5 $\mathrm{m}$ for maximum depth, $<1$ min for duration) were completely

Table 1. Callorhinus ursinus. Summary of northern fur seal pup satellite tracking during 1996-1998. (Dates are in GMT, given as mo/d/yr)

\begin{tabular}{|c|c|c|c|c|c|c|c|c|}
\hline Pup & $\begin{array}{c}\text { Deployment } \\
\text { date }\end{array}$ & $\begin{array}{l}\text { Departure } \\
\text { date }\end{array}$ & $\begin{array}{l}\text { Deployment- } \\
\text { departure (d) }\end{array}$ & $\begin{array}{c}\text { Exit } \\
\text { Bering }\end{array}$ & $\begin{array}{c}\text { Departure-exit } \\
\text { Bering (d) }\end{array}$ & $\begin{array}{c}\text { Final } \\
\text { transmission }\end{array}$ & $\begin{array}{l}\text { Sea days } \\
\text { tracked }\end{array}$ & $\begin{array}{c}\text { Total days } \\
\text { tracked }\end{array}$ \\
\hline 9650 & $11 / 10 / 96$ & $12 / 03 / 96$ & 23.0 & $>1 / 25 / 97$ & $>52$ & $1 / 25 / 97$ & 53.1 & 76.1 \\
\hline $96-51$ & $11 / 10 / 96$ & $11 / 21 / 96$ & 10.5 & $1 / 29 / 97$ & 68.6 & $2 / 16 / 97$ & 86.7 & 97.2 \\
\hline $96 \_52$ & $11 / 11 / 96$ & $11 / 19 / 96$ & 8.4 & $11 / 30 / 96$ & 10.6 & $1 / 23 / 97$ & 64.7 & 73.1 \\
\hline $96 \_54$ & $11 / 11 / 96$ & $11 / 12 / 96$ & 1.7 & - & - & $11 / 18 / 96$ & 5.4 & 7.1 \\
\hline 96_55 & $11 / 11 / 96$ & \multicolumn{3}{|c|}{ instrument failed upon deployment } & - & - & - & - \\
\hline 96_56 & $11 / 12 / 96$ & $11 / 14 / 96$ & 2.3 & $11 / 28 / 96$ & 13.7 & $3 / 30 / 97$ & 135.7 & 138.0 \\
\hline $96 \_57$ & $11 / 12 / 96$ & instrument & failed prior to $p$ & p's departure & - & $11 / 14 / 96$ & 0 & \\
\hline 96_58 & $11 / 12 / 96$ & $11 / 13 / 96$ & 1.3 & - & - & $11 / 17 / 96$ & 3.7 & 5.0 \\
\hline 97_50 & $11 / 08 / 97$ & $11 / 17 / 97$ & 8.6 & $12 / 14 / 97$ & 26.6 & $3 / 16 / 98$ & 118.7 & 127.3 \\
\hline 97_51 & $11 / 08 / 97$ & $11 / 12 / 97$ & 3.2 & $11 / 26 / 97$ & 14.0 & $5 / 07 / 98$ & 176.0 & 179.2 \\
\hline 97_52 & $11 / 09 / 97$ & $11 / 09 / 97$ & 0.6 & - & - & $11 / 10 / 97$ & 0 & 0.6 \\
\hline 97_53 & $11 / 09 / 97$ & $11 / 10 / 97$ & 1.0 & $>1 / 13 / 98$ & $>64$ & $1 / 13 / 98$ & 64.1 & 74.1 \\
\hline $97 \_54$ & $11 / 11 / 97$ & $11 / 26 / 97$ & 14.2 & $1 / 10 / 98$ & 45.7 & $5 / 20 / 98$ & 175.1 & 189.3 \\
\hline 97_55 & $11 / 11 / 97$ & $11 / 12 / 97$ & 0.6 & $12 / 05 / 97$ & 22.5 & $3 / 15 / 98$ & 122.7 & 123.3 \\
\hline 97_56 & $11 / 12 / 97$ & $11 / 18 / 97$ & 6.4 & 11/29/97 & 10.7 & $12 / 11 / 97$ & 22.7 & 29.1 \\
\hline 97_57 & $11 / 12 / 97$ & $11 / 14 / 97$ & 2.5 & 12/01/97 & 16.6 & $5 / 08 / 98$ & 174.7 & 177.2 \\
\hline $97 \_58$ & $11 / 13 / 97$ & $11 / 29 / 97$ & 16.5 & $12 / 08 / 97$ & 8.7 & $5 / 13 / 98$ & 164.7 & 181.2 \\
\hline $97 \_59$ & $11 / 12 / 97$ & $11 / 23 / 97$ & 10.5 & - & - & $11 / 30 / 97$ & 6.7 & 17.2 \\
\hline $97 \_60$ & $11 / 13 / 97$ & $11 / 20 / 97$ & 7.4 & $12 / 04 / 97$ & 13.7 & $5 / 09 / 98$ & 169.6 & 177.0 \\
\hline $97 \_61$ & $11 / 13 / 97$ & $11 / 21 / 97$ & 8.1 & - & - & $11 / 30 / 97$ & 9.0 & 17.1 \\
\hline
\end{tabular}



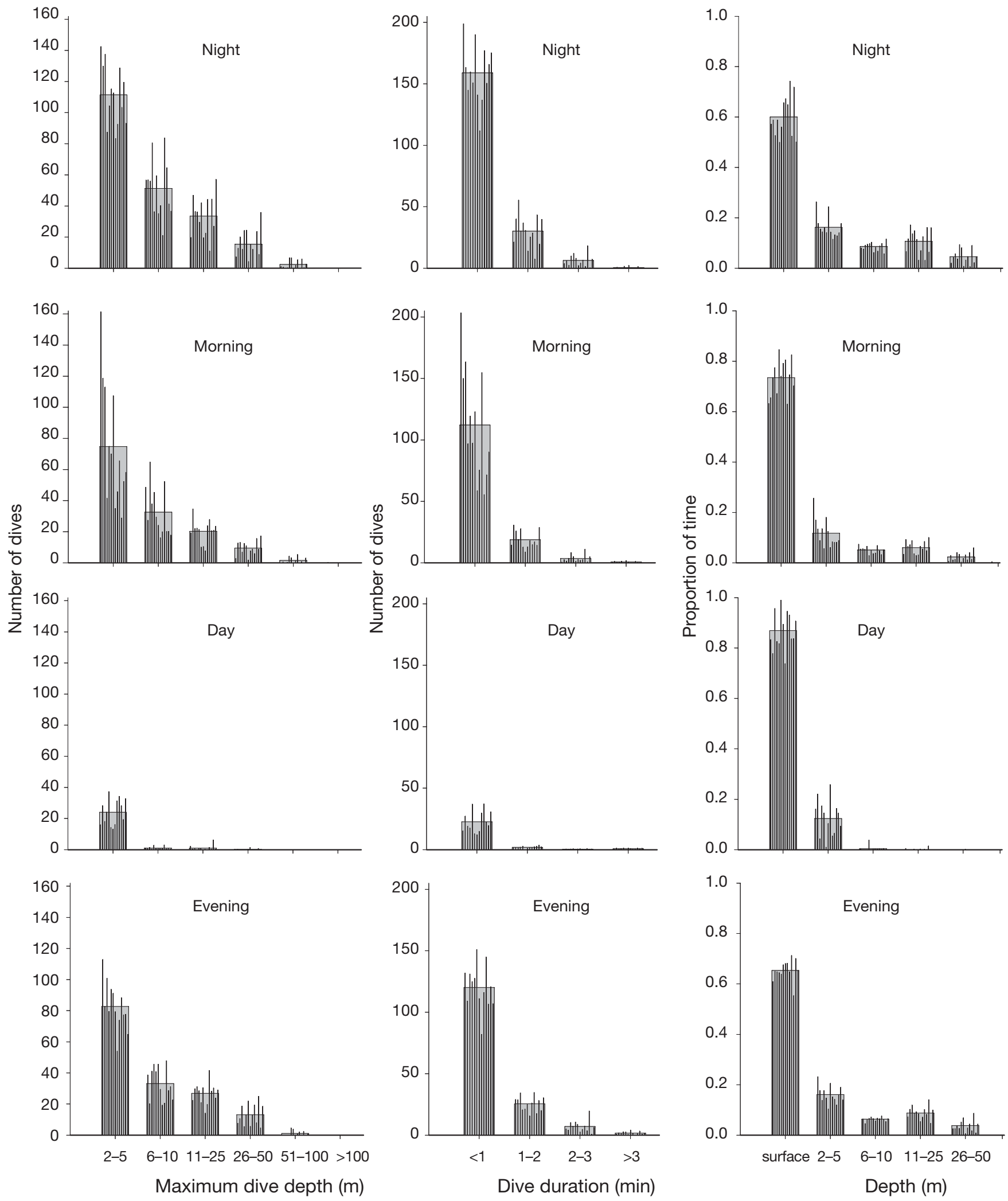

Fig. 6. Callorhinus ursinus. Diving behavior for 13 northern fur seal pups tracked for a minimum of $23 \mathrm{~d}$ at sea after onset of migration. Histograms of maximum dive depth, dive duration, and proportion of time at depth (from left to right) are presented for night $(21: 00-03: 00 \mathrm{~h})$, morning $(03: 00-09: 00 \mathrm{~h})$, day (09:00-15:00 h), and evening (15:00-21:00 h). Large gray bars indicate averages for these pups 


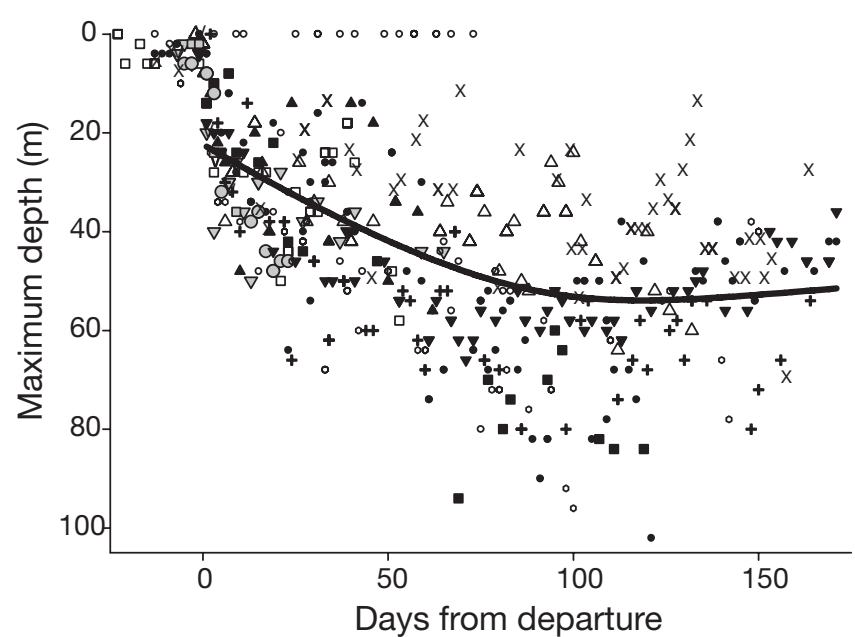

Fig. 7. Callorhinus ursinus. Maximum dive depth in a $24 \mathrm{~h}$ period for 15 northern fur seal pups plotted against time. Each pup is represented by a distinct symbol. The solid line is a second-order smooth function fitted to the combined observations for all 15 pups after the start of migration

filled. This rarely occurred for deeper or longer dive duration bins. As a result, summarized maximum depth and duration histogram data were skewed to some degree to the deeper and longer duration dives, as an unknown number of the shallowest and shortest dives were not counted. However, the time-at-depth histograms were not subject to overfilling, and these bins indicated very similar patterns to those for maximum dive depth.

Onset of migration appears to be an abrupt event, rather than a gradual process, as indicated by a variety of measures. Rather than making increasingly longer forays prior to departure, pups remained very near shore and quite close to their birth sites until the day they started their migration. Likewise, diving behavior apparently did not alter prior to departure. Shallow diving and very low percentage of time spent submerged are consistent with the conclusion of Baker \& Donohue (2000) that pups do not engage in appreciable pre-migration foraging. In contrast, New Zealand and Galapagos fur seals, which nurse $2 \times$ to $9 \times$ longer than northern fur seals, gradually increase diving activity and begin to forage prior to weaning (Horning \& Trillmich 1997, Baylis et al. 2005).

Given the Bering Sea's cold water temperatures and rough seas, it was somewhat surprising that 4 pups in this study remained there well into winter, and that 2 others were in Gulf of Alaska waters farther north than the Pribilof Islands when their records ended in spring. One might speculate that failing to exit the Bering Sea rapidly may be a fatal error for pups; however, the tracking technology used in this study does not allow one to discriminate between mortality and instrument failure, so that the survival repercussions of differing routes cannot be determined. However, Donohue et al. (2000) found that prior to migration pups are well-insulated by their fur and blubber, such that remaining in northerly waters may entail little energetic cost.

Pups used two completely separate groups of Aleutian Island passes to exit the Bering Sea in 1996 and 1997. Ragen et al. (1995) found that pups migrating in 1989 and 1990 transited a variety of passes, only some of which were used by pups in this study. Each of the 13 adult females that Ream et al. (2005) tracked in 2002 left via Unimak Pass, suggesting that these experienced migrators exhibit less variable navigation compared to naive pups that may wander more. However, subsequent tracking in 2004 had documented that adult females also used passes other than Unimak (R. R. Ream pers. comm.). Environmental cues or forcing (e.g. wind and currents) may vary among years and influence migration routes.

Two observations suggest a possible strategy that pups use to navigate, especially during early migration. One pup born on St. Paul departed and was next located on St. George Island; another pup born on St. George made the opposite trip to St. Paul. Both animals made the approximately $70 \mathrm{~km}$ open ocean crossing to arrive at a relatively small island less than $30 \mathrm{~h}$ after leaving their natal island for the first time. A parsimonious explanation for these seemingly unlikely feats of navigation is that the pups followed older seals familiar with the route. This suggests the hypothesis that naive pups may generally follow older seals. McConnell et al. (2002) made the same proposal to explain a weaned southern elephant seal pup's direct navigation across several hundred kilometers to islands it had not previously visited. Macy (1982) found that northern fur seal mothers and pups usually do not begin migration at the same time, so pups do not learn migration routes from their mothers. However, several hundred thousand older fur seals migrate during the same period as pups. Following an older animal would seem a better strategy than random trial, especially for a pup that had never ventured far from its birth site. Indeed, every older seal's existence is living proof of having successfully migrated in the past. Pups appear to have the ability to keep up with older animals. Ream et al. (2005) found adult females traveled $2.2 \mathrm{~km} \mathrm{~h}^{-1}$ on average in the Bering Sea, whereas the pups in this study averaged nearly as much (46 km d-1 or $1.9 \mathrm{~km} \mathrm{~h}^{-1}$ ) for the first $4 \mathrm{~d}$ of their migration. The two inter-island travelers noted above moved at least $2.3 \mathrm{~km} \mathrm{~h}^{-1}$.

For adult females leaving the Bering Sea, Ream et al. (2005) were able to distinguish a transit period from a destination because of their rather directed and sustained movements until they reached areas where they 
remained more stationary. In contrast, pups in this study typically alternated several fairly distinct periods of relatively directed movement with more sedentary intervals, and direction of movements varied greatly over time (Fig. 3). This may indicate that fur seal pups spend more time than adults searching for profitable foraging areas. Weaned southern elephant seals pups are perhaps more precocious. On their first extended trip to sea, elephant seal pups moved in a similar fashion as adults, with distinct phases of rapid, directed transit followed by a longer period characterized by relatively slower movements and many directional changes (McConnell et al. 2002).

\section{Diving behavior}

With the onset of migration, fur seal pups dramatically altered their dive patterns. They began making twice as many dives per day compared to the premigration period, diving deeper and longer, spending a higher proportion of their time submerged. They also switched from diving mostly during daylight hours to a pattern with the greatest amount of diving at night, somewhat less in the morning and evening, and virtually no diving during mid-day. This is similar to diving behavior noted for several fur seal species (e.g. Gentry et al. 1986, Boyd et al. 1991, Goebel et al. 1991, Harcourt et al. 1995, Georges et al. 2000, Goebel 2002, Lea et al. 2002), which suggests a strategy of foraging on vertically migrating organisms that descend out of range during the day. The abrupt switch in diving behavior suggests that pups may begin foraging right after departure. While there was some individual variation, the similarity in overall patterns among all pups was striking. Compared to the data available for older migrating northern fur seals, pups tended to dive to shallower depths (Ream et al. 2005). Far more diving data exists for adult females and juvenile males during the breeding season, which underscores that they can far outperform the patterns displayed by pups (Gentry et al. 1986, Goebel et al. 1991, Goebel 2002, Sterling \& Ream 2004). Because of their smaller size, migrating pups likely cannot exploit vertically migrating prey for the same length of time as older seals, and some prey resources available to older animals may be entirely unavailable to pups. Lower dive performance (i.e. dive duration, maximum depth, proportion of time submerged) of newly independent pinniped young, compared to adults, has been found in numerous species (Thorson \& Le Boeuf 1994, LeBoeuf et al. 1996, Horning \& Trillmich 1997, Burns et al. 1999, Hindell et al. 1999, Pitcher et al. 2005).

The increase in maximum dive depth during approximately the first $90 \mathrm{~d}$ post-migration may be influenced by decreasing buoyancy. Donohue et al. (2000) found that prior to migration, lipid stores make up approximately $33 \%$ of total body composition. This energy reserve may be expended to sustain pups during the early migration period while they learn to forage successfully. As fat stores are depleted and buoyancy consequently decreases, pups may descend more rapidly or otherwise dive with greater efficiency, allowing them to reach greater depth (cf. Webb et al. 1998, Beck et al. 2000).

Although the diving patterns of migrating pups were quite similar, they used a variety of habitats spread over a vast area, including pelagic waters as far south as $45^{\circ} \mathrm{N}$, coastal and continental shelf areas of Alaska, and the Alaska Gyre. While one can only speculate about how pups came to follow their respective paths, their wide dispersion is a potential mechanism for differential survival. Food availability, physical conditions (weather and water temperature), exposure to predation, and potential for interaction with fisheries may all vary among the areas used by migrating pups.

Distinct juvenile and adult dispersal patterns have been suggested as a mechanism for differential exposure to risks in long-distance migratory marine species. Weimerskirch et al. (2006) found that post-fledging, wandering albatross range in subtropical waters where productivity is lower and vulnerability to longline fishery mortality is higher than more productive waters where adult birds forage. Kooyman et al. (1996) found that emperor penguin juveniles travel further north from their natal colonies than adults and remain in ice-free waters where they cannot rest on ice floes available to adults at higher latitudes.

Most of the northern fur seal pups tracked in this study remained primarily in offshore areas, with only a few using coastal or shelf areas. Ream et al. (2005) found the opposite situation occurring among adult females, which primarily used continental shelf areas. This is consistent with the inference from at-sea collections that migrating pups tend to remain farther offshore (Kenyon \& Wilke 1953, Bigg 1990). Better characterization of habitats and hazards in offshore areas might be important for diagnosing the current population decline.

Acknowledgements. I am extremely grateful to T. Loughlin and K. Holser for their assistance in the field. B. Antonelis was integrally involved in the conception and planning of this study. R. Ream and M. A. Lea provided helpful reviews.

\section{LITERATURE CITED}

Baba N, Boltnev AI, Stus AI (2000) Winter migration of female northern fur seals Callorhinus ursinus from the Commander Islands. Bull Natl Res Inst Far Seas Fish 37:39-44 
Baker JD, Donohue MJ (2000) Ontogeny of swimming and diving in northern fur seal (Callorhinus ursinus) pups. Can J Zool 78:100-109

Barbraud C, Johnson AR, Bertault G (2003) Phenotypic correlates of post-fledging dispersal in a population of greater flamingos: the importance of body condition. J Anim Ecol 72:246-257

Bartholomew GA Jr, Hoel PG (1953) Reproductive behavior of the Alaska fur seal, Callorhinus ursinus. J Mammal 34:417-436

Baylis AMM, Page B, Peters K, McIntosh R, Mckenzie J, Goldsworthy S (2005) The ontogeny of diving behaviour in New Zealand fur seal pups (Arctocephalus forsteri). Can J Zool 83:1149-1161

Beck CA, Bowen WD, Iverson SJ (2000) Seasonal changes in buoyancy and diving behavior of adult grey seals. J Exp Biol 203:2323-2330

Bigg MA (1990) Migration of northern fur seals (Callorhinus ursinus) off western North America. Can Tech Rep Fish Aquat Sci 1764

Block BA, Teo SLH, Walli A, Boustany A and 5 others (2005) Electronic tagging and population structure of Atlantic bluefin tuna. Nature 434:1121-1127

Boyd IL, Lunn NJ, Barton T (1991) Time budgets and foraging characteristics of lactating Antarctic fur seals. J Anim Ecol 60:577-592

Burns JM, Castellini MA, Testa JW (1999) Movements and diving behavior of weaned Weddell seal (Leptonychotes weddellii) pups. Polar Biol 21:23-36

Clarke J, Knowles K, Fowler C, Lawless R, Eberhard S, Murphy R (2003) Post-fledging and winter migration of Adélie penguins Pygoscelis adeliae in the Mawson region of East Antarctica. Mar Ecol Prog Ser 248:267-278

Donohue MJ, Costa DP, Goebel ME, Baker JD (2000) The ontogeny of metabolic rate and thermoregulatory capabilitites of northern fur seal, Callorhinus ursinus, pups in air and water. J Exp Biol 203:1003-1016

Gentry RL, Holt JR (1986) Attendence behavior of northern fur seals. In: Gentry RL, Kooyman GL (eds) Fur seals: maternal strategies on land and at sea. Princeton University Press, Princeton, NJ, p 41-60

Gentry RL, Costa DP, Croxall JP, David JHM and 5 others (1986) Synthesis and conclusions. In: Gentry RL, Kooyman GL (eds) Fur seals: maternal strategies on land and at sea. Princeton University Press, Princeton, NJ, p 220-264

Georges JY, Tremblay Y, Guinet C (2000) Seasonal diving behavior in lactating subAntarctic fur seals on Amsterdam Island. Polar Biol 23:59-69

Goebel ME (2002) Northern fur seal lactation, attendance and reproductive success in two years of contrasting oceanography. $\mathrm{PhD}$ dissertation, University of California, Santa Cruz, CA

Goebel ME, Bengtson JL, DeLong RL, Gentry RL, Loughlin TR (1991) Diving patterns and foraging locations of female northern fur seals. Fish Bull 89:171-179

Hake M, Kjellen N, Alerstam T (2003) Age-dependent migration strategy in honey buzzards Pernis apivorus tracked by satellite. Oikos 103:385-396

Harcourt RG, Schulman AM, Davis LS, Trillmich F (1995) Summer foraging by lactating female New Zealand fur seals (Arctocephalus forsteri) off Otago Peninsula, New Zealand. Can J Zool 73:678-690

Hindell MA, McConnell BJ, Fedak MA, Slip DJ, Burton HR, Reijnders PJH, McMahon CR (1999) Environmental and physiological determinants of successful foraging by naive southern elephant seal pups during their first trip to sea. Can J Zool 77:1807-1821
Horning M, Trillmich F (1997) Ontogeny of diving behaviour in the Galapagos fur seal. Behaviour 134:1211-1257

Kenyon KW, Wilke F (1953) Migration of the northern fur seal Callorhinus ursinus. J Mammal 34:86-98

Kooyman GL, Kooyman TG, Horning CA, Kooyman CA (1996) Penguin dispersal after fledging. Nature 383:397

Lander RH (1979) Role of land and ocean mortality in yield of male Alaskan fur seal, Callorhinus ursinus. Fish Bull 77 : 311-314

Lea MA, Hindell M, Guinet C, Goldsworthy S (2002) Variability in the diving activity of Antarctic fur seals, Arctocephalus gazella, at Iles Kerguelen. Polar Biol 25:269-279

Le Boeuf BJ, Morris PA, Blackwell SB, Crocker DE, Costa DP (1996) Diving behaviour of juvenile northern elephant seals. Can J Zool 74:1632-1644

Loughlin TR, Antonelis GA, Baker JD, York AE, Fowler CW, DeLong RL, Braham HW (1994) Status of the northern fur seal population in the United States during 1992. In: Sinclair EH (ed) Fur seal investigations, 1992. NOAA Tech Memo NMFS-AFSC-45, p 9-28

Loughlin TR, Ingraham JW Jr, Baba N, Robson BW (1999) Use of a surface-current model and satellite telemetry to assess marine mammal movements in the Bering Sea. In: Loughlin TR, Ohtani K (eds) Dynamics of the Bering Sea: a summary of physical, chemical, and biological characteristics, and a synopsis of research on the Bering Sea. University of Alaska Sea Grant, Fairbanks, AK, p 615-630

Macy SK (1982) Mother-pup interactions in the northern fur seal. PhD dissertation, University of Washington, Seattle, WA

McConnell B, Fedak M, Burton HR, Engelhard GH, Reijnders PJH (2002) Movements and foraging areas of naïve, recently weaned southern elephant seal pups. J Anim Ecol 71:65-78

McGrady MJ, Maechtle TL, Vargas JJ, Seegar WS, Catalina Porras Peña M (2002) Migration and ranging of peregrine falcons wintering on the Gulf of Mexico coast, Tamaulipas, Mexico. Condor 104:39-48

Peterson RS (1968) Social behavior in pinnipeds with particular reference to the northern fur seal. In: Harrison RJ, Hubbard RC, Peterson RS, Rice CE, Schusterman RJ (eds) The behavior and physiology of pinnipeds. AppletonCentury-Crofts, New York, p 3-53

Pitcher KW, Rehberg MJ, Pendleton GW, Raum-Suryan KL, Gelatt TS, Swain UG, Sigler MF (2005) Ontogeny of dive performance in pup and juvenile Steller sea lions in Alaska. Can J Zool 83:1214-1231

Polovina J, Uchida I, Balazs G, Howell EA, Parker D, Dutton P (2006) The Kuroshio Extension Bifurcation Region: a pelagic hotspot for juvenile loggerhead sea turtles. DeepSea Res II 53:326-339

Ragen TJ, Antonelis GA, Kiyota M (1995) Early migration of northern fur seal pups from St. Paul Island, Alaska. J Mammal 76:1137-1148

Ream RR, Sterling JT, Loughlin TR (2005) Oceanographic features related to northern fur seal migratory movements. Deep-Sea Res II 52:823-843

Robson BW, Goebel ME, Baker JD, Ream RR, Loughlin TR, Francis RC, Antonelis GA, Costa DP (2004) Separation of foraging habitat among breeding sites of a colonial marine predator, the northern fur seal (Callorhinus ursinus). Can J Zool 82:20-29

Service Argos (1996) User manual. Service Argos, Toulouse

Shaffer SA, Tremblay Y, Weimerskirch H, Scott D and 7 others (2006) Migratory shearwaters integrate oceanic resources across the Pacific Ocean in an endless summer. Proc Natl Acad Sci USA 103:12799-12802 
Sterling JT, Ream RR (2004) At sea behavior of juvenile male northern fur seals (Callorhinus ursinus). Can J Zool 82:1621-1637

Thorson PH, Le Boeuf BJ (1994) Developmental aspects of diving in northern elephant seal pups. In: Le Boeuf BJ, Laws RM (eds) Elephant seals: population ecology, behavior, and physiology. University of California Press, Berkeley, CA, p 271-289

Towell RG, Ream RR, York AE (2006) Decline in fur seal (Callorhinus ursinus) pup production on the Pribilof Islands. Mar Mamm Sci 22:486-491

Webb PM, Crocker DE, Blackwell SB, Costa DP, LeBoeuf BJ (1998) Effects of buoyancy on the diving behavior of northern elephant seals. J Exp Biol 201:2349-2358

Editorial responsibility: Rory Wilson (Contributing Editor), Swansea, UK
Weimerskirch H, Wilson RP (2000) Oceanic respite for wandering albatross. Nature 406:955-956

Weimerskirch H, Åkesson S, Pinaud D (2006) Postnatal dispersal of wandering albatrosses Diomedea exulans: implications for the conservation of the species. J Avian Biol $37: 23-28$

Weng KC, Castilho PC, Morrissette JM, Landeira-Fernandez AM, Holts DB, Schallert RJ, Goldman KJ, Block BA (2005) Satellite tagging and cardiac physiology reveal niche expansion in salmon sharks. Science 310:104-106

York AE, Hartley JR (1981) Pup production following harvest of female northern fur seals. Can J Fish Aquat Sci 38:84-90

Zar JH (1984) Biostatistical analysis. Prentice-Hall, Englewood Cliffs, NJ

Submitted: September 29, 2006; Accepted: January 12, 2007 Proofs received from author(s): June 22, 2007 